\title{
Fuga de padrões e a figura da mulher em contos machadianos: pos- síveis influências feministas
}

Avoiding standards and the image of the woman in Machado de Assis's short stories: possible feminist influences

Ariel Erick Paulo de Souza, Cláudio Rodrigo Gomes da Silva, Lucas Ferreira Rodrigues da Silva, Rafael Italo Fernandes da Fonseca.

Como citar esse artigo. Souza AEP, Silva CRG, Silva LFR, Fonseca RIF. Fuga de padrões e a figura da mulher em contos machadianos: possíveis influências feministas. Revista Mosaico. 2013 Jan./Jun.; 04 (1): 23-28.

\begin{abstract}
Resumo
Não somente o magnum opus de Machado de Assis contém as características de suas técnicas literárias. Embora muito mais se tenha a dizer do autor através de seus romances, este artigo empenha-se em sugerir um cenário de possíveis relações entre as personagens femininas subjugadoras dos contos "A Cartomante", "Singular Ocorrência" e "Noite de Almirante" e os discursos da primeira onda do feminismo, da qual o tempo de vida do escritor brasileiro foi integrante. Palavras-Chave: Machado de Assis. Feminismo. Mulher do século XIX.
\end{abstract}

\begin{abstract}
Not only Machado de Assis's magnum opus has the features of his literary techniques. Although we can say a lot more about the author by his novels, the article aims to suggest a scenario of possible relation between the overwhelming female characters from the short stories "A Cartomante", "Singular Ocorrência" e "Noite de Almirante" and the discourses of the first wave of feminism, during which the author's lifetime was part of. Keywords: Machado de Assis. Feminism. XIX century women.
\end{abstract}

\section{O feminismo e o conto machadiano}

Machado de Assis viveu entre 1839 e 1908, época em que esteve evidente a primeira onda do feminismo, movimento de mulheres pela conquista de espaço social e também político do gênero. Não se encontram registros suficientes para que se dê conta do ano exato do início do feminismo, mas sabe-se do discurso "Ain't I a Woman?" - da empregada doméstica nova-iorquina, na condição de escrava, Sojourner Truth - proferido em Ohio e datado de 1851, quando já existiam feministas.

Apenas o fato de os anos combinarem não dá conta, porém, de explicitar as relações existentes entre o ideário de Machado sobre a mulher exposto nos contos "A Cartomante" (1884), "Singular Ocorrência" (1884) e "Noite de Almirante" (1883) e a primeira onda do movimento feminista. Embora as datas específicas em que os contos em questão foram publicados configurem o auge desse primeiro momento, faz-se necessário postular outros fatores que viabilizem essa comparação histórico-literária a que visa este trabalho.

Alguns nomes importantes para essa primeira "fase" foram Voltairine de Cleyre, Margaret Sanger e, em 1820, nos Estados Unidos Susan Brownell Anthony, feminista que, reivindicando importância aos direitos da mulher, publicou alguns pontos de vista sobre o casamento. Neles, Anthony sintetiza e abre espaço sobre proferimentos feministas que, dentre outros tantos, estabelecem relação com a personalidade emancipatória das mulheres desses contos de Machado.

É-se necessário sugerir a influência que os dezenove anos a mais de Anthony trouxeram para o escritor brasileiro. Os pensamentos feministas não ficaram restritos aos Estados Unidos, nem à Europa, e seria adequado pensar no fato de que tudo que Susan produziu se encontrava quase vinte anos à frente de Machado de Assis.

Entre os pontos de vista da americana, contam-se 
reflexões acerca do direito da mulher de recusa à relação sexual com o marido e, especialmente, acerca do direito que tem a mulher sobre o próprio corpo, incluindo, entre outros pontos, decisões sobre abstinência e aborto.

Rogel Samuel faz registros sobre o momento histórico e acaba por pontuar características da técnica literária das obras machadianas analisadas:

\begin{abstract}
"Opropósito da crítica literária feminista anglo-americanae de toda a investigação feminista é o de expor os mecanismos que mantêm a sociedade patriarcal, com o objetivo de transformar as relações sociais. [...] As feministas defendem a atividade de transformar a sociedade, porque também acreditam que a sociedade patriarcal está a serviço dos interesses dos homens sobre os da mulher. Seu tema é o modo de como a sociedade patriarcal as oprime." (SAMUEL, 2011, p. 184)
\end{abstract}

O escritor brasileiro era parte integrante do Realismo literário e, por conseguinte, apresentava o que Hênio Tavares chama de "preferência pelos assuntos da época".

\begin{abstract}
"O sentido do contemporâneo contrasta com a evasão romântica através do passado ou do futuro. A preocupação do realista é fixar os sucessos da época, qualquer acontecimento ou conflito do homem com seu meio ambiente, do qual ele não é espectador remoto e ausente, mas testemunha próxima e presente." (TAVARES, 2002, p. 78)
\end{abstract}

Machado imprime nos contos reflexões sobre temas pertinentes, como o contraste entre o senso formal do casamento e a verdade sobre as relações de infidelidade conjugal. Os contos aqui analisados traçam universos. Cada um dos elementos do contraste supramencionado é, nessa ótica, um universo. O escritor aborda "passeios" das personagens femininas desses contos por entre os dois espaços e deflagra uma provável influência dos postulados feministas da época em sua escrita, quando propõe que a mulher é que toma iniciativa em cada câmbio de universo e, por este fato, o faz independente da ciência ou da aprovação do marido.

Nesse contexto, em que o casamento é composto de uma relação exclusiva, independente de fatores externos ou empecilhos, qualquer posição emancipatória da personagem feminina na ficção configura pura e clara sugestão de influência feminista. $\mathrm{O}$ direito a si e ao fato de poder gerir a própria vida amorosa (casada ou não) confere à mulher a liberdade por que tanto lutaram as feministas daquele tempo, na Europa ou nos Estados Unidos.

Sabe-se que a produção de um literato e seu contexto situacional são elementos de uma relação que se dá em consonância, especialmente na escola realista. Machado relata mais que casos isolados, retrata um fato social. É difícil pensar em um grupo feminino discursando em uníssono, agindo conforme um padrão de relacionamento unilateral no Brasil, enquanto ecoam no exterior outras vozes, proferimentos de liberdade e autonomia de gênero.

Odiscurso do velho bruxo, homem de antonomásia consagrada, atrela-se às propostas do feminismo e os três contos aqui abordados, ele faz saltar de um plano de paradigmas que envolvem descrições do tradicional casamento oitocentista, de cunho patriarcal e, por isso, centralizador.

Machado de Assis conhecia seus interlocutores. A seção de composição literária dos periódicos da época era, em sua maioria, de leitura feminina. Equiparava-se à atual telenovela. O jornal era, além de um mecanismo de publicidade e informação, um campo de transmissão de pontos de vista. No Romantismo, o que caracterizava a interação periódico-leitora era aquela retratação da burguesa, a descrição fluente; para Machado, a quebra de protótipos. Não eram poucas as mulheres que viviam com seus maridos submissamente, embora sem revide. $\mathrm{O}$ escritor brasileiro não só apresenta mulheres de realidades conjugais fora dos padrões, mas também convida a reflexões através da ficção. Insere a necessidade de se repensar o papel da mulher perante o marido.

Os contos do velho bruxo são dotados de subjetividade, sendo necessário analisar atentamente sua conceituada obra para que detalhe algum deixe de ser percebido durante a leitura. Além da subjetividade, é interessante ressaltar a importância que o autor emprega a expressões cotidianas, como um simples olhar, fazendo diferença ímpar devido a sua singularidade, que atribui características de cunho impactante à suas personagens. Inferências extrapoladas são, assim, possíveis, caso uma leitura detalhada não se concretize.

\section{A Cartomante}

$\mathrm{Na}$ análise deste conto, é possível enxergar características da primeira onda feminista na principal personagem feminina da história: Rita, esposa de Vilela, que - ao mudar-se para o Rio com o marido - cria grande afinidade com Camilo, melhor amigo de Vilela. Com ele vem a ter um forte romance. Romance esse, que vem a se tornar a essência da trama, pondo em choque as realidades desses três personagens supracitados.

Rita "realmente, era graciosa e viva nos gestos, olhos cálidos, boca fina e interrogativa." (ASSIS, 2007, p. 53) Essas são as primeiras características da personagem observadas por Camilo, que já mostram uma personagem com grande poder sedutor. Uma mulher graciosa que pode não somente agradar aos olhos do marido, mas também ser um troféu frente aos amigos e fazer-lhes inveja. Essa qualidade também, na maioria das vezes, agrada aos familiares. Mães, avós, pais e irmãos, normalmente, sentem orgulho e ficam satisfeitos quando esse tipo de mulher passa a fazer 
parte da família e a cuidar de um de seus membros. Olhos cálidos e boca fina mostram uma mulher de beleza física natural e grande poder de atratividade através de seu olhar. Belas formas, unidas à sua já mencionada graciosidade, tornam-na um espetáculo aos olhos de qualquer pessoa. Desejo, paixão e lamentos por parte dos homens, que, possivelmente, não foram poucos a lhe procurar; admiração e inveja por parte de outras mulheres, já que muitas fariam de tudo para ter todos esses dotes. Contudo, são as outras características citadas as de maior relevância na personagem. Com seus gestos vivos e ar interrogativo, Rita alcança outra esfera de poder. Além dos atributos físicos e sociais, ela possui elevados níveis mentais e psicológicos, o que a transformam em um ser altamente forte e seguro. Uma mulher que além de chamar a atenção dos homens, pode também fasciná-los. Sabe-se bem que uma mulher graciosa e bela pode ser o sonho de consumo de muitos homens, mas que essa ambição pode ser muito bem satisfeita, após não muito tempo de romance. Muitas vezes um único dia é suficiente. Rita, diferentemente da maioria das mulheres, possui características que poderiam enlouquecer homens, casados e solteiros. Características que não são comuns às mulheres de sua época. Como citado anteriormente neste artigo, a mulher desta época, muitas vezes, era graciosa e dotada de beleza natural, mas as detentoras deste poder de sedução, segurança e ar misterioso não eram muitas. Muitas vezes, inclusive, as que os tinham não eram bem vistas, posto que a sedução feminina era tida, por boa parte da sociedade, como a arte das meretrizes.

Tudo leva a crer que Rita era um personagem de pulso, longe do estereótipo de esposa da época: apática, submissa e vivendo para agradar ao marido. E logo em seguida é apresentada outra importante característica de Rita: "Era um pouco mais velha que ambos: contava trinta anos, Vilela vinte e nove e Camilo vinte e seis." (Ibid.) Outro fato que rompe os paradigmas da época. Habitualmente os homens se casavam com mulheres muito mais jovens, algumas vezes com metade de sua idade ou menos. Não seria estranho ver um homem da idade de Vilela casado com uma moça com menos de vinte anos de idade. Mas Rita mesmo sendo mais velha, inclusive que o marido, desbancou as rivais jovens. Conclui-se que havia certamente rivais, visto que Vilela não era qualquer um. Como dito anteriormente no conto, abriu banca de advogado ao se mudar para o Rio de Janeiro. O modelo de bom marido aos olhos da sociedade é o homem bem sucedido profissional e financeiramente, o que é levado a crer sobre o personagem de Vilela. Ao observar-se omarido percebemos mais essência feminista em Rita. Casou-se com um homem não somente mais jovem, mas também bem sucedido. Tem-se margem então para outras inferências a respeito da mesma. Um número ainda maior de rivais possivelmente foi vencido por ela. Um advogado, com boas condições financeiras, aos vinte e nove anos de idade, provavelmente teve uma série de pretendentes. Pode-se concluir, também, que Rita teria um alto nível de ambição para os padrões de sua época, pois teria se decidido a ter Vilela mesmo esse sendo mais jovem e também endinheirado. Outro fator importante a ser analisado em torno do casamento entre os dois é que na época em que viviam (século XIX) muitos ainda viam o casamento como um acordo entre partes, prática que tinha muita predominância até o século XVIII e que ainda se mostrava muito presente na sociedade da época. Nessa perspectiva, casamento e amor não têm ligação, acontecendo com a função de assegurar a transmissão de heranças, estabelecer alianças entre famílias e manutenção/melhoria das condições financeiras dos envolvidos. Rita com sua forte personalidade não se submeteu a este capricho da sociedade machista, escolhendo ela seu parceiro, conquistando-o e concretizando o matrimônio.

Certos hábitos incomuns a mulheres em Rita são dignos de nota: "Liam os mesmos livros, iam juntos a teatros e passeios. Camilo ensinou-lhe as damas e o xadrez e jogavam às noites". (Ibid.) Em relação aos passeios, nada mais normal do que a esposa acompanhar o marido. Mas, no que diz respeito aos livros e jogos podemos notar uma curiosidade e gosto intelectual na personagem, nada comum na sociedade feminina do século dezenove. Ao início dos flertes entre os futuros amantes é notável a personalidade forte e as atitudes decididas de Rita: "os olhos teimosos de Rita, que procuravam muita vez os dele, que os consultavam antes de o fazer ao marido, as mãos frias, as atitudes insólitas." (Ibid.) Nada da mulher apática e submissa parece haver no interior da personagem, que toma atitudes enérgicas e põe seu casamento em risco na presença do marido para cortejar o homem pelo qual se sente atraída. O fogo da paixão em Rita dava a ela, através de sua personalidade forte, a coragem para realizar ações que outras mulheres sequer conseguiriam cogitar.

Não supreendentemente, Rita consegue com seus dons femininos conquistar completamente Camilo, apesar de ele ter tentado evitar a situação em prol do amigo:

\footnotetext{
"Camilo quis sinceramente fugir, mas já não pôde. Rita, como uma serpente, foi-se acercando dele, envolveu-o todo. Fez-lhe estalar os ossos num espasmo e pingou-lhe o veneno na boca. Ele ficou atordoado e subjugado. Vexame, sustos, remorsos, desejos, tudo sentiu de mistura; mas a batalha foi curta e a vitória delirante. Adeus escrúpulos! Não tardou que o sapato se acomodasse ao pé, e aí foram ambos, estrada à fora, baços dados, pisando folgadamente por cima de ervas e pedregulhos, sem padecer nada mais que algumas saudades, quando estavam ausentes um dos outro." (Ibid., p. 54)
}

Mais claro e nítido torna-se nesse ponto o poder da personagem: Rita, com todo sucesso, conquista absolutamente o melhor amigo do marido deixando-o totalmente submisso à sua vontade. Mais uma vez, 
características fortemente feministas são mostradas pela personagem, que age como bem entende: motivada por suas próprias vontades e conduzida por suas capacidades.

A personagem apesar de toda a sua força e segurança é ainda um ser humano. Não deixou de perturbar-se, quando as cartas, que provavam haver mais alguém sabendo de seu romance com Camilo, começaram a chegar. Angústia e aflição tomaram conta de sua mente, até mais que da de seu amante. Contudo, a forma como Rita encarou essa adversidade é mais uma prova de sua natureza intensamente feminista. Crê-se que muitas das mulheres em seu lugar acabariam ali mesmo o romance e dedicariam cada um dos futuros dias de suas vidas a desejar que o marido nunca soubesse e que as cartas finalmente parassem de chegar. Outras, tentariam cultivar na cabeça do marido a ideia de uma nova mudança de endereço, ou mesmo de cidade. Na verdade, é complicado fazer muitas inferências sobre esse ponto, já que poucas mulheres contemporâneas de Rita teriam tomado algumas das decisões que a colocaram em tal situação. Mas podemos afirmar como a forma pró ativa e decidida com que reagiu demonstram que era, sim, um ser humano que não estava livre das perturbações e inseguranças que assolam todos os demais, mas que tinha pulso para buscar, ela mesma, soluções para tal. Apesar do ceticismo do amante, e provavelmente dela mesma, visto que compartilhavam de muitos traços intelectuais que normalmente vão contra a crença no oculto, a personagem busca respostas em uma consulta com uma cartomante. "Ria, ria. Os homens são assim; não acreditam em nada. Pois saiba que fui [...]" (Ibid., p. 51): foi como Rita deu a notícia a Camilo. Suas palavras que pouco se importavam com a opinião do parceiro quanto à sua decisão de procurar a cartomante e de acreditar em suas palavras sobrenaturais. Foi até ela, antes mesmo de consultá-lo se deveria ou não e, da mesma forma, apropriou-se dessas palavras, sentindose satisfeita. Só então resolveu contar a ele a história, mostrando, mais uma vez, que sabia muito bem o que queria (e como queria) sem precisar de permissão ou sequer de conselhos do amado.

\section{Singular Ocorrência}

O conto "Singular ocorrência" foi publicado na coletânea Histórias sem data, em 1884, e narra a história de Marocas, uma prostituta que, ao se apaixonar por Andrade, larga sua antiga profissão para viver só para ele. No conto, se observa a ambiguidade como traço de uma crítica à sociedade patriarcal, caracterizando, portanto um feminismo sugerido no conto machadiano.

O conto é narrado em primeira pessoa e se apresenta limitado ao ponto de vista do narradortestemunha, bem como ao tempo decorrido do acontecimento, sendo, portanto, difícil comprovar a veracidade do fato. Todos os acontecimentos levam o leitor a seguir o ponto de vista do narrador que, sendo amigo de Andrade, o descreve como um homem de família rica "meio advogado, meio político" (ASSIS apud ROCHA, 2008, p. 126) enquanto Marocas: "Deve chamar-se hoje D. Maria de tal" (Ibid., p. 125). O narrador, durante todo o conto descreve Marocas como inferior ao seu amigo, Andrade, o que caracteriza uma tendência de época: a desvalorização da mulher, frente ao homem.

Quando o narrador afirma que Marocas: "ficou só, sozinha vivendo para o Andrade, não querendo outra afeição, não cogitando de nenhum outro interesse" (Ibid., p.127) o narrador acentua uma suposta inferioridade, por parte de Marocas. Quando Andrade se retira por dois dias pela ocasião da festa de São João, ele espera que Marocas se contente com a postura submissa da mulher oitocentista e fique sozinha, enquanto ele, em posição de superioridade sai para festejar com sua família na Gávea, o que não se concretiza na singular personagem Machadiana. A possibilidade da traição, por parte de uma mulher, vem a ser uma transgressão aos valores patriarcais vigentes na sociedade, tendo em vista que as mulheres, na época, eram vistas como submissas aos homens, fato observado nesse mesmo conto, no discurso do narrador, portanto, em uma época em que as mulheres não cogitavam a possibilidade de sequer levantar a voz para os homens; trair significava que ela não fazia parte daquele pensamento e que também não compactuava com aquela realidade.

De acordo com Maia Neto (2007), Machado teve muita influência de pensadores renascentistas como Montaigne e Pascal, que negavam a existência da certeza quanto à veracidade de qualquer informação, caracterizando-se, portanto o pensamento cético típico do movimento de meados do século XVI, o qual Machado de Assis vem retomar no Brasil do século XIX. Sendo assim, nas obras machadianas observa-se que não existem verdades absolutas e, consequentemente, tudo o que uma pessoa tem por verdade pode não ser verdade para outra pessoa. Cria-se com isso uma diferença baseada meramente no ponto de vista.

A ambiguidade se apresenta no conto, como um traço da mulher feminista, tão singular no século XIX, isso se evidencia no conto, quando Andrade ouve de Leandro o relato da suposta traição, perdendo a razão e ficando desnorteado com o acontecido. "Ele mesmo não soube o que fez nem o que disse, durante os primeiros minutos, nem o que pensou nem o que sentiu". (ASSIS apud ROCHA, 2008, p. 129) Andrade, ao se perder em suas dúvidas propõe, em troca de vinte mil réis, que Leandro confesse seus relatos diante de Marocas que empalidece ao vê-los juntos. 
"A cena que se seguiu, foi breve, mas dramática. Não a soube inteiramente, porque o próprio Andrade é que me contou tudo, e, naturalmente, estava tão atordoado, que muita coisa lhe escapou. Ela não confessou nada; mas estava fora de si." (Ibid., p. 130)

Quando Marocas deixa de confessar, cria-se uma segunda ambiguidade quanto ao fato da traição, pois há a possibilidade de ela tê-lo traído, assim como também há a possibilidade de ela ter simulado uma traição com seu amigo, Leandro, como uma forma de protesto pelo fato de Andrade tê-la deixado sozinha, enquanto aproveitava a festa com sua família. As duas possibilidades são características do ceticismo Machadiano muito presente no conto e ficam expostas quando o próprio Andrade cogita essa possibilidade.

"Do furor passou à duvida; chegou a imaginar que Marocas, com o fim de o experimentar, inventara o artifício e pagara ao Leandro para vir dizer-lhe aquilo [...]. E agarrado a esta inverossimilhança, tentava fugirà realidade [...].(Ibid.,p. 131)

Quando o narrador admite desconhecer inteiramente a cena que se seguiu, ele confirma a restrição de seu ponto de vista, já que o próprio Andrade não soube muito bem o que aconteceu. Andrade, então, descobre que Marocas saiu de casa desesperada e pôsse rapidamente a procurá-la. "Contive o Andrade, cujo primeiro gesto foi para sair logo". (Ibid.) No século XIX, em geral eram as mulheres que procuravam seus maridos após a traição, em razão de serem submissas a eles, no entanto, o personagem machadiano Andrade vai de encontro a sua amada, o que caracteriza uma inversão de valores fazendo com que no conto, o homem adquira posição de inferioridade em relação à mulher. Andrade e seu amigo procuraram por Marocas durante toda a noite até que, no dia seguinte, conseguiram notícias que os levou a uma hospedaria.

"Encaminhamo-nos para o quarto; o dono da hospedaria bateu à porta; ela respondeu com voz fraca, e abriu. $\mathrm{O}$ Andrade nem me deu tempo de preparar nada; empurroume, e caíram nos braços um do outro.” (Ibid., p. 133)

Quando o interlocutor pergunta se tudo se explicou, o narrador afirma que nenhum deles voltou a falar sobre o assunto sendo que a reconciliação fez-se depressa e, por mais que o narrador acredite na traição, Andrade abandona todas as aflições ao se encontrar com Marocas perdoando-a instantaneamente, o que o narrador critica como sendo uma "nostalgia da lama". O conto é, sobretudo, uma crítica à injusta sociedade brasileira do século XIX, incluindo seus ideais patriarcais e seu moralismo hipócrita que a todos julgava e apenas às elites perdoava.

\section{Noite de Almirante}

Neste ponto, será analisada a figura da mulher e sua transgressão à vontade masculina, através do conto "Noite de Almirante", cuja retratação das mulheres da época era de figuras fiéis e que se entregavam apenas a seus maridos com total devoção sem ao menos contestarem.

Ao analisar o conto em questão, evidencia-se, em um primeiro momento, o sentimento mútuo de Genoveva e Deolindo. Este último, por se tratar de um marinheiro, necessita sair em alto mar para uma jornada de dez meses, o que colocaria em prova o sentimento que nutriam um pelo outro. Sabendo disso, Deolindo faz um juramento à Genoveva, que compartilha do mesmo. Nele, acordam que esperariam o período de ausência em fidelidade. Tal afirmação é percebida através do seguinte trecho:

“[...] Deolindo não teve remédio senão seguir em viagem de instrução. Eram oito ou dez meses de ausência. Como fiança recíproca, entenderam dever fazerumjuramento defidelidade.

- Juro por Deus que está no céu. E você?

- Eu também.

- Diz direito.

- Juro por Deus que está no céu; a luz me falte na hora da morte. Estava celebrado o contrato." (ASSIS apud ROCHA, 2008, p. 136)

O agravante no conto é o fato de Genoveva não cumprir com sua palavra, com seu juramento de amor, pois não resistira à solidão que a acompanhava. Percebe-se então, que a necessidade de um alguém a seu lado fez com que não cumprisse com seu juramento e se envolvesse com outro homem.

Tomando por base o parágrafo supracitado, que pontua de forma compreensível a posição tomada pela personagem, é notável a posição incomum de Genoveva, que para o modelo de mulher que vivia no séc. XIX, não transparecia a consciência prosaica das demais mulheres de mesma época, as quais se submetiam a seus maridos e suas vontades, fossem sociais ou sexuais. A partir desse excerto, nota-se o não cumprimento das juras feitas por Genoveva, uma transgressão de valores morais, de fidelidade, que a personagem atestava possuir, mesmo ao reencontrar seu antigo amado, como está evidenciado no trecho transcrito:

“- Pode crer que pensei muito e muito em você. Sinhá
Inácia que lhe diga se não chorei muito... Mas o coração
mudou... Mudou... Conto-lhe tudo isto, como se estivesse
diante do padre, concluiu sorrindo.” (Ibid., p. 139)

O que se deve observar de maneira crítica a respeito da obra, além da figura da mulher não cumprindo seu juramento, é o fato de assumir uma característica que não era de seu feitio, uma vez que durante a descrição da personagem pelo autor: mulher 
que se apaixonara, que detinha vontade de se entregar, inclusive de fugir com Deolindo, se fosse necessário, mulher esta, que fez com que seu amado acreditasse em suas juras. Contudo em um segundo momento, a mesma personagem apresenta outra mentalidade, sem perder a racionalidade ou capacidade argumentativa para tentar convencer Deolindo que o amou de verdade, como fora exemplificado no trecho anteriormente transcrito.

Há nesse momento uma percepção de dois universos, um em que existe uma mulher apaixonada, da mulher fiel, que se submete e o outro em que insatisfeita com a espera, rompe com seu "compromisso" e se torna uma adúltera ideológica, pois embora não houvesse sido realizada uma cerimônia religiosa ou mesmo união civil, havia entre ambos, comum acordo em esperar o tempo necessário para ficarem juntos.

Nessa perspectiva, a personagem de Genoveva faz transição de um universo em que é fiel,, que é amada, no entanto à distância, de uma maneira que não a satisfaz e se deixa conduzir para um outro em que deveria possuir um homem ao seu lado, que cuidasse dela. Todavia, ao fazê-lo, ela assume papel de homem do século XIX, no sentido de poder se relacionar com outra pessoa sem ressentir ou recear a reação de seu parceiro, ou seja, personagem passa a agir de forma que suas necessidades, seu íntimo fosse estimulado.

Tomando tal posicionamento, a personagem inverte a ordem natural dos relacionamentos da época, onde o homem era o transgressor, o homem detinha a autoridade dentro do convívio do casal, ao tomar a decisão de seguir seus instintos carnais, por assim dizer, Genoveva, passa a ter o sentimento de Deolindo sob seu controle.

Outro aspecto importante na obra é a instabilidade da fidelidade de Genoveva, apesar de deter o controle dos sentimentos de Deolindo e de José Diogo, homem pelo qual a personagem afirma ter se apaixonado após a partida de seu antigo amado, há um período de imprecisão na obra na qual se percebe claramente o abalo na conduta de Genoveva, após esta receber de Deolindo os brincos que comprara em Trieste para presentear-lhe:

"- Sim, senhor, muito bonitos, disse ela, fazendo uma grande mesura de agradecimento. Onde é que comprou? Creio que ele não respondeu nada, não teria tempo para isso, porque ela disparou mais duas ou três perguntas, uma atrás da outra, tão confusa estava de receber um mimo a troco de um esquecimento.” (Ibid., p. 141)

Neste trecho, ao receber o presente de Deolindo, Genoveva tem, como reação, torrentes de perguntas, o interesse, de certa forma, reavivada através de um simples agrado, consecutivamente após questionar se ele havia pensado nela durante o período de embarcação. A simples ação de presentear, termina com as dúvidas de Genoveva, que demonstra a partir deste momento, mais interesse acerca das histórias que Deolindo possui, ou seja, é possível perceber que a personagem apenas age segundo seu próprio desejo e interesse, no intuito de satisfazer suas ambições não se importando com os demais ao redor, característica da mulher contemporânea em pleno séc. XIX, na obra Machadiana.

Outra característica e habilidade, por assim dizer, da personagem, é a capacidade de induzir no homem o sentimento da dúvida, embora Deolindo soubesse que Genoveva não renovaria seus votos, aproveitando-se da ausência de José Diogo, e o interesse suspeito de Genoveva, pondera sobre uma possibilidade remota de haver uma reconciliação, expresso no texto:

"Genoveva acendeu uma vela. Depois foi sentar-se na
soleira da porta e pediu-lhe que contasse alguma coisa
das terras por onde andara. Deolindo recusou a princípio;
disse que se ia embora, levantou-se e deu alguns
passos na sala. Mas o demônio da esperança mordia e
babujava o coração do pobre diabo, e ele voltou a sentar-
se, para dizer duas ou três anedotas de bordo." (Ibid.)

O trecho supracitado serve de embasamento para a teoria levantada acerca do comportamento e da mentalidade de Genoveva, para manipular, instintivamente ou não, Deolindo de forma a fazê-lo momentaneamente reavaliar seus sentimentos, ponderar sua situação para com a mulher que amava.

Sendo assim, Machado conseguiu atribuir a seus personagens características que, para a época, possuiam conceitos comportamentais bastante desenvolvidos, formas de estabelecer e tratar um relacionamento. Seus personagens, em pleno século XIX, estabelecem relação direta com o cotidiano, apesar da distância cronológica, Machado fez, a partir suas criações literárias, espécie de contato com a realidade. Principalmente no que diz respeito à figura feminina, além de retratar a mudança no comportamento, ressaltou a importância de a mulher ter direito de preservar sua vontade, seu corpo e principalmente seus valores e crenças, o que, certamente, para o período em que escrevia foi um avanço ideológico de proporção imensurável.

\section{Referências}

ASSIS, M. Contos Escolhidos. São Paulo: Martin Claret, 2007.

CURTHOYS, A. Adventures of Feminism: Simone de Beauvoir's Autobiographies, Women's Liberation, and Self-Fashioning. Feminist Review, Basingstoke: Palgrave Macmillan Journals, n. 64, pp. 3-18. 2000.

MAIA NETO, José Raimundo. O ceticismo na obra de Machado de Assis. São Paulo: Annablume, 2007.

ROCHA, J. C. C. (org.). Contos de Machado de Assis: adultério e ciúme. Vol. 2. Rio de Janeiro: Record, 2008.

SAMUEL, R. Novo Manual de Teoria Literária. Petrópolis: Vozes, 2011. 